Case Report

\title{
Plesiomonas shigelloides Septic Shock Leading to Death of Postsplenectomy Patient with Pyruvate Kinase Deficiency and Hemochromatosis
}

\author{
Mohammed Samannodi, Andrew Zhao, Yaser Nemshah, and Kevin Shiley \\ Department of Medicine, Buffalo Mercy Hospital, University at Buffalo, Buffalo, NY 14220, USA \\ Correspondence should be addressed to Mohammed Samannodi; samannodi@gmail.com
}

Received 10 April 2016; Accepted 1 August 2016

Academic Editor: Sinésio Talhari

Copyright (c) 2016 Mohammed Samannodi et al. This is an open access article distributed under the Creative Commons Attribution License, which permits unrestricted use, distribution, and reproduction in any medium, provided the original work is properly cited.

\begin{abstract}
Although Plesiomonas shigelloides, a water-borne bacterium of the Enterobacteriaceae family, usually causes self-limiting gastroenteritis with diarrhea, several cases of sepsis have been reported. We report the case of a 43-year-old male patient with hemochromatosis, pyruvate kinase deficiency, and asplenia via splenectomy who developed septic shock caused by P. shigelloides complicated by respiratory failure, renal failure, liver failure, and disseminated intravascular coagulation. Early aggressive antimicrobial therapy and resuscitation measures were unsuccessful and the patient passed away. We kindly suggest clinicians to implement early diagnosis of septic shock, empirical coverage with antibiotics, and prompt volume resuscitation based on the high mortality rate of $P$. shigelloides bacteremia.
\end{abstract}

\section{Introduction}

Plesiomonas shigelloides is an oxidase-positive, anaerobic gram negative bacillus bacteria of the Enterobacteriaceae family which normally reside in soil and fresh water environments including the Great Lakes. P. shigelloides is also distributed among warm- and cold-blooded animals like dogs and seafood. Its method of infection is contamination of the gastrointestinal tract via consumption of raw fish or water-contaminated foods [1-6].

Plesiomonas shigelloides usually causes self-limited diarrheal illness but can also lead to extraintestinal infections with immunocompromised patients and patients with underlying hepatobiliary disease like hemochromatosis [7-13]. Bacteremia caused by $P$. shigelloides is very rare with only 36 reported cases with our case being the 36th. In addition, the literature has shown a significant mortality associated with $P$. shigelloides sepsis in 16 cases with ours being the latest one $[7,8,10,11,13-16]$.

\section{Case Presentation}

A 43-year-old Caucasian gentleman with past medical history of homozygous hereditary hemochromatosis and pyruvate kinase deficiency leading to a splenectomy at 4 years of age was admitted to the Buffalo Mercy Hospital with a threehour history of fever, chills, and generalized weakness. The patient denied any recent travel or sick contacts. The only recent change at home was the addition of a new puppy that infrequently bit and scratched him. The patient also reported that one week ago he had eaten home-cooked clams. Lastly, he swam in Lake Erie on many occasions over the past month. During that period of time, local health officials had closed off that particular beach several times because of elevated coliform levels.

On examination, he had a temperature of $39.5^{\circ} \mathrm{C}$, heart rate 120 beats $/ \mathrm{min}$, blood pressure $80 / 50 \mathrm{mmHg}$, and respiratory rate 18 breaths $/ \mathrm{min}$. The rest of his dental, chest, abdomen, skin, and neurological exams including meningeal signs were unremarkable. A complete blood count revealed leukocytosis with bandemia (WBC 17.1, bands 28\%) and macrocytic anemia (Hgb $8.3 \mathrm{~g} / \mathrm{dL}, \mathrm{MCV}: 129.5 \mathrm{dL}$ ) while a complete metabolic panel showed renal failure (BUN $18 \mathrm{mg} / \mathrm{dL}$, creatinine $3.55 \mathrm{mg} / \mathrm{dL}$ ) and liver failure (ALT $2500 \mathrm{U} / \mathrm{I}$, AST $5000 \mathrm{U} / \mathrm{I}$, total bilirubin $14.5 \mathrm{mg} / \mathrm{dL}$, indirect bilirubin $10 \mathrm{mg} / \mathrm{dL}$, and ALP $262 \mathrm{U} / \mathrm{I})$. Additional laboratory findings included lactic acidosis $(179.1 \mathrm{mg} / \mathrm{dL})$ with $\mathrm{ABG}$ 
TABLE 1: Minimal inhibitory concentrations of various antibiotics for Plesiomonas shigelloides.

\begin{tabular}{lc}
\hline Antibiotics & Minimal inhibitory concentrations $(\mathrm{mg} / \mathrm{mL})$ \\
\hline Cefepime & $\leq 1$ \\
Ceftriaxone & $\leq 1$ \\
Ciprofloxacin & $\leq 0.25$ \\
Gentamicin & 4 \\
Imipenem & $\leq 0.25$ \\
Levofloxacin & $\leq 0.12$ \\
Piperacillin/tazobac & $\leq 4$ \\
Tobramycin & 2 \\
Trimethoprim/sulfa & $\leq 20$ \\
\hline
\end{tabular}

showing high anion gap metabolic acidosis. Electrocardiogram showed only sinus tachycardia. Transthoracic echocardiogram was unremarkable. Computed tomograms of head, chest, and abdomen were unremarkable. Two blood cultures and urine culture were performed. The patient was diagnosed with septic shock.

Aggressive volume resuscitation measures were started along with empiric coverage utilizing intravenous ceftriaxone and vancomycin. The patient developed respiratory failure soon after. Because of worsening renal failure, he also later underwent hemodialysis. On the second day of admission, the blood cultures returned and showed gram negative rods while the urine culture was negative. Total iron and ferritin were performed and returned $196 \mu \mathrm{g} / \mathrm{dL}$ and $1350.2 \mathrm{mg} / \mathrm{mL}$ respectively. Disseminated intravascular coagulopathy developed (PTT 74.2 seconds, PT 37.1 seconds, INR $3.2 \mathrm{U} / \mathrm{I}$, fibrinogen $40 \mathrm{mg} / \mathrm{dL}$, fibrinogen degradation products $60 \mu \mathrm{g} / \mathrm{mL}$, and platelets 55) and the multiorgan failure continued to worsen. As the patient's condition continued to deteriorate, levofloxacin and tobramycin were added to the ongoing antibiotic therapy. Using VITEK2 for microbial identification and antibiotic susceptibility testing, the final blood culture identified the gram negative rods as Plesiomonas shigelloides. The organism was found to be susceptible to a multitude of different antibiotics including the patient's regimen of ceftriaxone, levofloxacin, and tobramycin (Table 1). Despite aggressive attempts at resuscitation, the patient's condition further worsened and he passed away on the third day of hospitalization.

\section{Discussion}

In this case report, the patient had three possible sources for $P$. shigelloides infection: the addition of a new puppy, recent consumption of clams, and illegal swimming in Lake Erie. In addition, he also had a medical history of homozygous hereditary hemochromatosis and pyruvate kinase deficiency which led to a splenectomy during childhood. The latter condition played a role by increasing the patient's risk of infection while compromising his immune response to bacteria. The former pointed towards previous cases that also involved patients with haematological conditions, including thalassemia intermedia, hemochromatosis, and sickle betazero thalassemia $[10,13,15]$. Another study demonstrated that $P$. shigelloides uses heme as a source of iron and it had been hypothesized that chronic iron overload in said conditions can predispose patients to infections $[13,15,17]$. We recommend further studies to be performed in the future particularly to establish the association between $P$. shigelloides' heme use system and the effect of chronic iron overload relating to infections.

Bacteremia caused by Plesiomonas shigelloides is a very rare complication with 36 reported cases worldwide including this presented case $[7,8,10,11,13-16]$. However, out of those 36 cases, 16 patients expired, which demonstrates a mortality rate of $44 \%$. The majority of cases of $P$. shigelloides sepsis involve neonates and patients with immunocompromising conditions such as leukemia, immunosuppression after allogeneic bone marrow transplantation, and HIV [716]. Based on the nature of these patients and the high mortality rate associated with $P$. shigelloides bacteremia, we highly recommend early diagnosis of septic shock and early administration of antimicrobials and volume resuscitation. While our patient did not survive even with multiple antibiotic therapy and resuscitation methods, the risks of bacteremia and septic shock still merit a very similar aggressive approach to treatment.

Finally, although this was not done at the time, we suggest that systemic corticosteroid administration may also be beneficial in cases of refractory shock. Septicemia, especially in association with septic shock, has been known to cause adrenal infraction leading to adrenal insufficiency [18].

\section{Disclosure}

This case was presented as a poster in the 2015 New York Chapter ACP Annual Scientific Meeting Poster Competition and was later published in the poster book as a Resident Fellow Clinical Vignette.

\section{Competing Interests}

The authors (Mohammed Samannodi, Andrew Zhao, Yaser Nemshah, and Kevin Shiley) declare that there are no competing interests regarding the publication of this paper.

\section{References}

[1] R. A. Brenden, M. A. Miller, and J. M. Janda, "Clinical disease spectrum and pathogenic factors associated with Plesiomonas shigelloides infections in humans," Reviews of Infectious Diseases, vol. 10, no. 2, pp. 303-316, 1988.

[2] M. L. Miller and J. A. Koburger, "Plesiomonas shigelloides: an opportunistic food and waterborne pathogen," Journal of Food Protection, vol. 48, no. 5, pp. 449-457, 1985.

[3] J. Janda and S. Abbott, The Enterobacteria, ASM Press, Washington, DC, USA, 2006.

[4] T. Arai, N. Ikejima, T. Itoh, S. Sakai, T. Shimada, and R. Sakazaki, "A survey of Plesiomonas shigelloides from aquatic environments, domestic animals, pets and humans," Journal of Hygiene, vol. 84, no. 2, pp. 203-211, 1980. 
[5] C. Mahon and G. Manuselis, Textbook of Diagnostic Microbiology, Saunders, Philadelphia, Pa, USA, 3rd edition, 2007.

[6] W. A. Davis, J. H. Chretien, V. F. Garagusi, and M. A. Goldstein, "Snake-to-human transmission of aeromonas (Pl) shigelloides resulting in gastroenteritis," Southern Medical Journal, vol. 71, no. 4, pp. 474-476, 1978.

[7] A. C. W. Lee, K. Y. Yuen, S. Y. Ha, D. C. K. Chiu, and Y. L. Lau, "Plesiomonas shigelloides septicemia: case report and literature review," Pediatric Hematology and Oncology, vol. 13, no. 3, pp. 265-269, 1996.

[8] P. C. Y. Woo, S. K. P. Lau, and K.-Y. Yuen, "Biliary tract disease as a risk factor for Plesiomonas shigelloides bacteraemia: a nineyear experience in a Hong Kong hospital and review of the literature," New Microbiologica, vol. 28, no. 1, pp. 45-55, 2005.

[9] C. Terpeluk, A. Goldmann, P. Bartmann, and F. Pohlandt, "Plesiomonas shigelloides sepsis and meningoencephalitis in a neonate," European Journal of Pediatrics, vol. 151, no. 7, pp. 499501, 1992.

[10] M. L. Delforge, J. Devriendt, Y. Glupczynski, W. Hansen, and N. Douat, "Plesiomonas shigelloides septicemia in a patient with primary hemochromatosis," Clinical Infectious Diseases, vol. 21, no. 3, pp. 692-693, 1995.

[11] P. A. Riley, N. Parasakthi, and W. A. Abdullah, "Plesiomonas shigelloides bacteremia in a child with leukemia," Clinical Infectious Diseases, vol. 23, no. 1, pp. 206-207, 1996.

[12] O. Ozdemir, S. Sari, S. Terzioglu, and A. Zenciroglu, "Plesiomonas shigelloides sepsis and meningoencephalitis in a surviving neonate," Journal of Microbiology, Immunology and Infection, vol. 43, no. 4, pp. 344-346, 2010.

[13] M. Auxiliadora-Martins, F. Bellissimo-Rodrigues, J. M. Viana et al., "Septic shock caused by Plesiomonas shigelloides in a patient with sickle beta-zero thalassemia," Heart \& Lung: The Journal of Acute and Critical Care, vol. 39, no. 4, pp. 335-339, 2010.

[14] A. Z. Young, D. Neujahr, and L. Estok, "Epididymo-orchitis and bacteremia caused by Plesiomonas shigelloides in an HIVinfected patient," AIDS Reader, vol. 11, no. 12, pp. 617-619, 2001.

[15] V. Kalotychou, Y. Rombos, R. Tzanetea et al., "Plesiomonas shigelloides sepsis in a thalassemia intermedia patient," Scandinavian Journal of Infectious Diseases, vol. 34, no. 9, pp. 687-689, 2002.

[16] X. Chen, Y. Chen, Q. Yang et al., "Plesiomonas shigelloides infection in Southeast China," PLoS ONE, vol. 8, no. 11, Article ID e77877, 2013.

[17] A. L. Oldham, T. A. Wood, and D. P. Henderson, "Plesiomonas shigelloides hugZ encodes an iron-regulated heme binding protein required for heme iron utilization," Canadian Journal of Microbiology, vol. 54, no. 2, pp. 97-102, 2008.

[18] D. Annane, E. Bellissant, P.-E. Bollaert et al., "Corticosteroids in the treatment of severe sepsis and septic shock in adults: a systematic review," Journal of the American Medical Association, vol. 301, no. 22, pp. 2362-2375, 2009. 


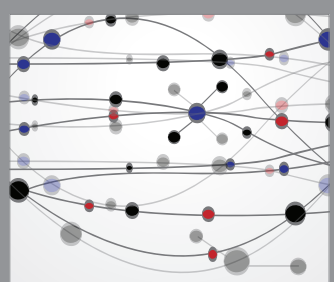

The Scientific World Journal
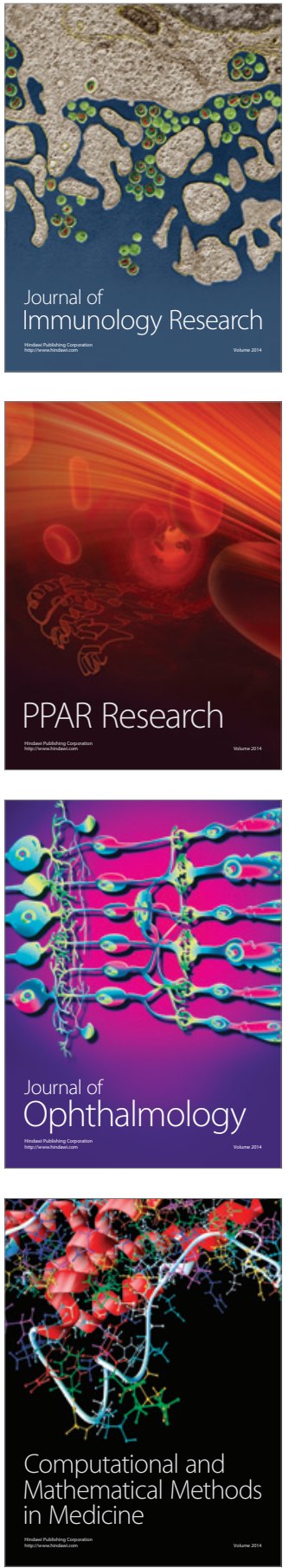

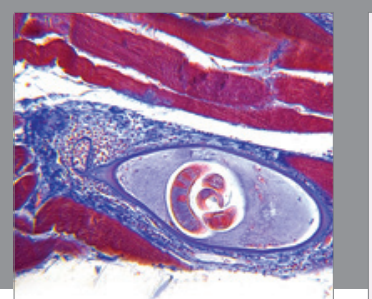

Gastroenterology Research and Practice

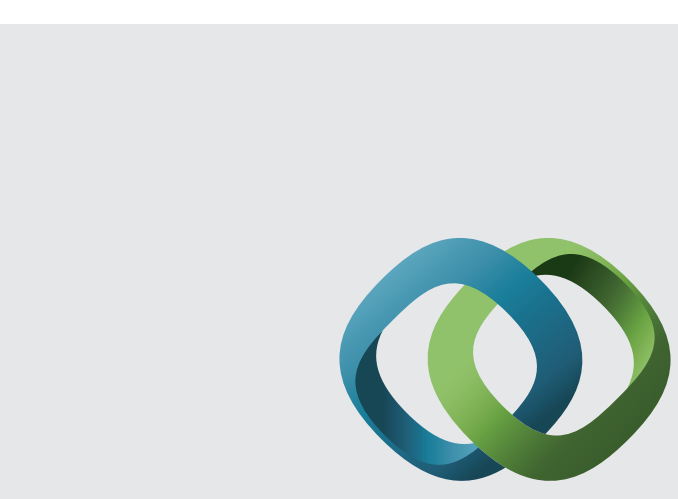

\section{Hindawi}

Submit your manuscripts at

http://www.hindawi.com
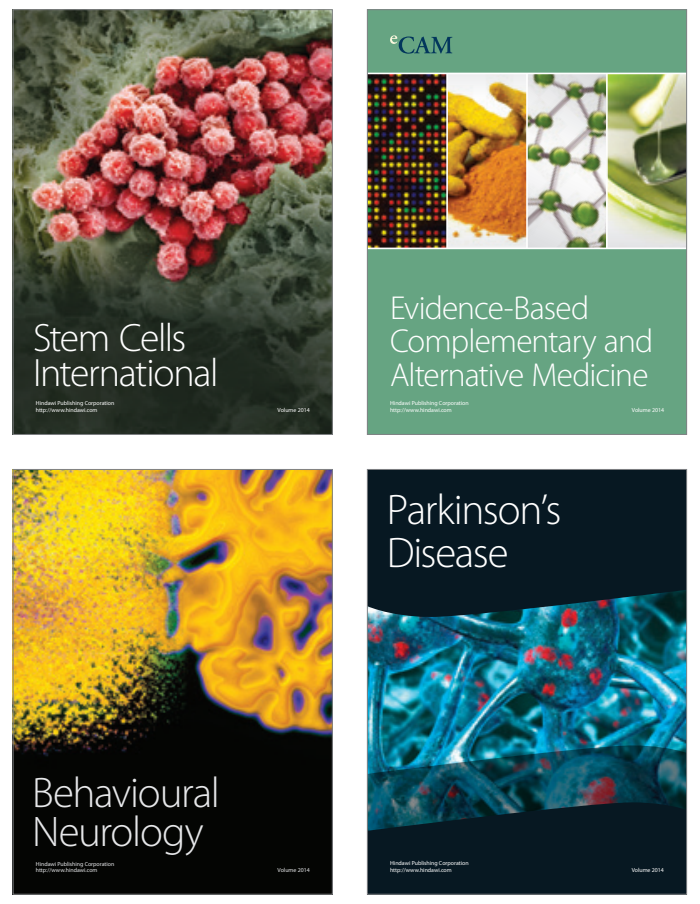
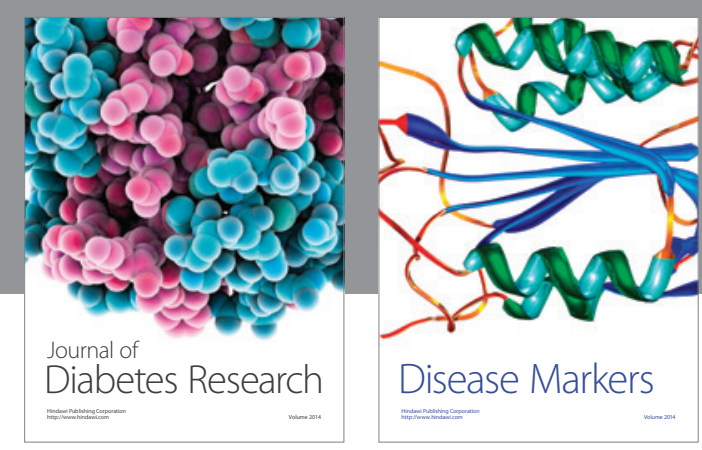

Disease Markers
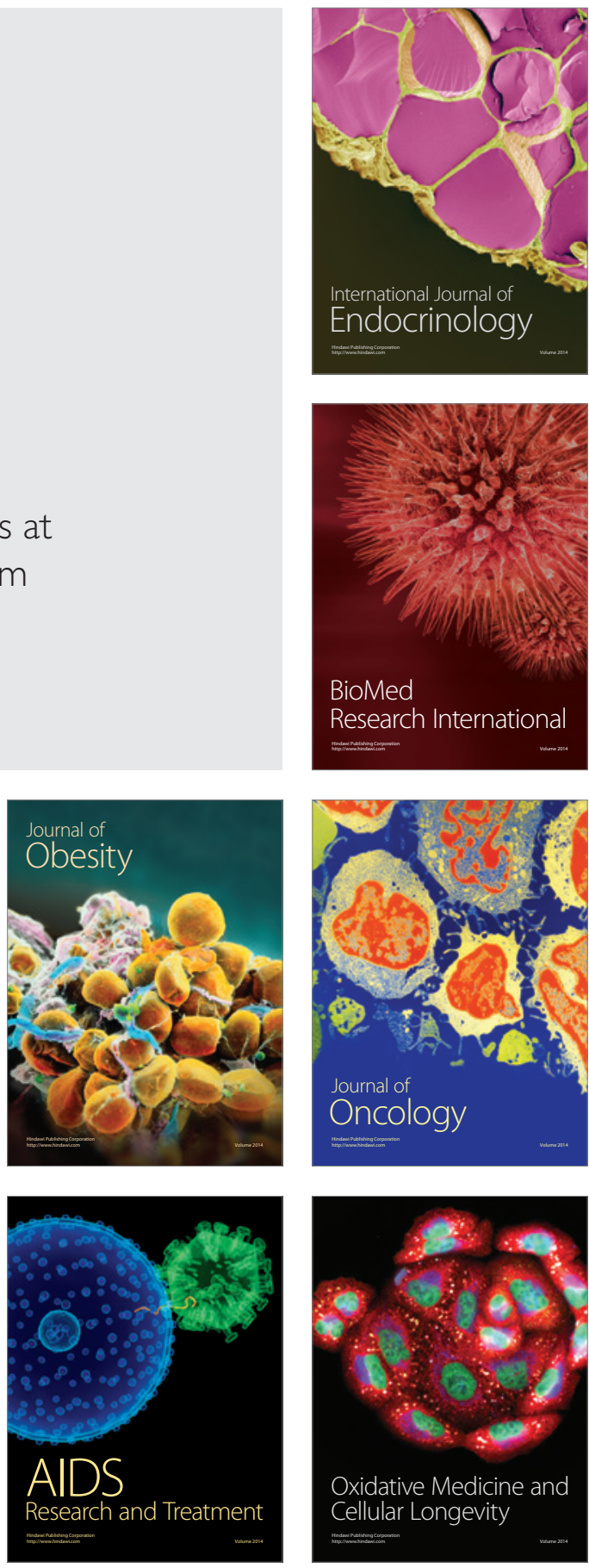